\title{
EFEITO DA IDADE DE CORTE NA PERFORMANCE DE TRÊS FORRAGEIRAS DO GÊNERO Cynodon ${ }^{1}$
}

\author{
JORGE ALBERTO GIRÓN CEDEÑO ${ }^{2}$ \\ GUDESTEU PORTO ROCHA ${ }^{3}$ \\ JOSÉ CARDOSO PINTO ${ }^{4}$ \\ JOEL AUGUSTO MUNIZ ${ }^{5}$ \\ ELISANGELA MINATI GOMIDE ${ }^{6}$
}

\begin{abstract}
RESUMO - O experimento foi conduzido em área do Departamento de Zootecnia da Universidade Federal de Lavras, de novembro do 2000 a maio de 2001, com o objetivo de avaliar a performance de três cultivares do gênero Cynodon em quatro idades de corte $(28,42,56$ e 70 dias) quanto ao rendimento e valor nutritivo. As cultivares estudadas foram Coastcross (Cynodon dactylon (L.) Pers. cv. Coastal x Cynodon nlemfuensis Vanderyst var. robustus), Tifton 68 (Cynodon spp) e Tifton 85 (Cynodon spp). Os tratamentos foram estabelecidos sob delineamento em blocos ao acaso, esquema de parcelas subdivididas, com cinco repetições; sendo as cultivares de gramíneas (= tratamentos) alocadas nas parcelas e as idades de corte nas subparcelas. Observou-se que, independentemente das cultivares estudadas, a produção de
\end{abstract}

\begin{abstract}
MS, com o avanço do estádio de maturidade, cresceu de forma quadrática (2,15 a 11,09 t/ha), atingindo pontos máximos de produção aos 70 dias. Os teores de PB apresentaram uma correlação negativa linear com a idade de corte, decrescendo de 17,18 a 11,04\% de PB aos 28 e 70 dias de crescimento, respectivamente. Por outro lado, o teor de FDN apresentou correlação positiva com a idade de corte, sofrendo incrementos com o avanço da idade de corte. Já os coeficientes de DIVMS diminuíram de forma quadrática com o avanço da idade, variando de 65,11 a $51,50 \%$ aos 28 e 70 dias, respectivamente. Conclui-se que independente da cultivar de gramínea, a melhor idade de corte ocorre entre 35 a 48 dias, momento em que há um bom rendimento e valor nutritivo da forragem.
\end{abstract}

TERMOS PARA INDEXAÇÃO: Cynodon, idades, rendimento de MS, PB, FDN, DIVMS.

\section{EFFECT OF HARVESTING AGES IN THE PERFORMANCE OF THREE GRASSES OF THE Cynodon GENUS}

\begin{abstract}
The experiment was carried out in the Animal Science Department at the Federal University of Lavras from November, 2000 to May, 2001. Its objective was to evaluate the performance, the yield, and the nutritive value of three cultivars of the genus Cynodon in four harvesting ages $(28,42,56$, and 70 days). The grasses tested were Coastcross (Cynodon dactylon (L.) Pers. cv. Coastal x Cynodon nlemfuensis Vanderyst var. robustus), Tifton 68 (Cynodon spp), and
\end{abstract}

Tifton 85 (Cynodon spp). The treatments were done in a completely randomised blocks design in a split plot scheme with five replications. The grass cultivars (= treatments) were placed in the plots and the harvesting ages were in the subplots. Regardlessly the studied cultivars, the dry matter production, with the advance of the maturity stage, increased in a quadratic way $(2,15$ to $11,09 \mathrm{Mg} / \mathrm{ha}$ ), reaching the maximum production at 70 days. The total protein contents

1. Parte da tese apresentada à UNIVERSIDADE FEDERAL DE LAVRAS/UFLA, Caixa Postal 37 - 37200-000 - Lavras, MG, pelo primeiro autor, para obtenção do título de Mestre em Zootecnia - Forragicultura e Pastagens.

2. Engenheiro Zootecnista da Universidade de Panamá (FCA), Av. Central Santa Maria, Herrera, Panamá - República de Panamá. cedenogiron8@hotmail.com

3. Engenheiro Agrônomo, DSc., Professor do Departamento de Zootecnia da UFLA.

4. Engenheiro Agrônomo, DSc., Professor do Departamento de Zootecnia da UFLA.

5. Engenheiro Agrônomo, DSc., Professor do Departamento de Ciências Exatas da UFLA.

6. Estudante de graduação do DZO/UFLA. 
showed a linear negative correlation with harvesting age, decreasing from 17,18 to $11,04 \%$ at 28 and 70 days. On the other hand, the neutral detergent fiber content showed a positive correlation with harvesting age, having increments with the increase of the age. The in vitro dry matter digestibility coefficients showed a quadratic negative relation with the harvesting age, varying from 65,11 to $51,50 \%$ at 28 and 70 days. It is concluded that regardlessly the cultivar, the best harvesting period occurs from 35 to 48 days, period that provides good yield and high nutritive value in the grasses.

INDEX TERMS: Cynodon, harvesting age, dry matter, total protein, neutral detergent fiber, in vitro dry matter digestibility, yield.

\section{INTRODUÇÃO}

As pastagens apresentam um alto potencial de produção animal a baixo custo, quando utilizadas de forma eficiente. Com a intensificação da produção animal, estratégias e conhecimentos de manejo para melhorar os índices de produtividade vegetal e animal tornamse necessários, fazendo com que os sistemas de produção animal se tornem mais rentáveis e economicamente sustentáveis em regime exclusivo de pastejo.

Grande parte da informação gerada até hoje por pesquisas com gramíneas do gênero Cynodon foi desenvolvida em experimentos conduzidos no sudeste dos EUA, cujos resultados mostraram elevado potencial produtivo e altos valores protéicos e de digestibilidade. Esses estudos concentraram-se na exploração de gramíneas sob condições de pastejo e de produção de feno, especificamente para alimentar bovinos de corte em sistemas semi-intensivos (Burton et al., 1993).

As gramíneas Tiftons e Coastcross são de alto potencial de produção e relativamente novas no Brasil, tornando-se necessário determinar os ecossistemas nos quais apresentam melhor desempenho. Atualmente, são utilizadas em algumas fazendas no Brasil em sistemas intensivos de pastejo com animais leiteiros de alto potencial de produção, já que apresentam uma alta capacidade de suporte e uma alta resposta à adubação nitrogenada.

Os capins Tifton 68 e Tifton 85 (Cynodon spp) foram desenvolvidos pelo Departamento de Agricultura dos Estados Unidos, Universidade da Geórgia, (USDAUniversity of Geórgia), pela equipe do Professor Dr. Glenn W. Burton, sendo considerado o Tifton 85 o melhor híbrido F1 originado da introdução sul-africana PI290884 cruzamento com o Tifton 68 (Burton et al., 1993; Vilela \& Alvim, 1998).

O capim Tifton 68 (Cynodon spp) é um híbrido F1 do cruzamento de duas introduções, a PI255450 e a PI293606, as mais digestíveis provenientes do Quênia, África Oriental (Burton \& Monson, 1984). Por outro lado, a gramínea Coastcross (Cynodon dactylon (L.) Pers. cv. Coastal x Cynodon nlemfuensis Vanderyst var. ro- bustus) é o resultado do cruzamento entre a grama bermuda Coastal e uma introdução de bermuda PI255445 de alta digestibilidade, pouco tolerante ao frio (Botrel et al., 1998).

O estágio de desenvolvimento da planta apresenta ampla relação com a composição química e a qualidade das forrageiras. Com o crescimento das forrageiras, ocorrem aumentos nos teores de carboidratos estruturais e lignina, o que invariavelmente proporciona redução na digestibilidade; são também alteradas as estruturas das plantas com a elevação da relação caule/folha, e as plantas mais velhas apresentam maiores proporções de talos que de folhas, tendo, portanto, reduzido o seu conteúdo em nutrientes potencialmente digeríveis com a maturação (Reis \& Rodrigues, 1993).

A redução nos teores de proteína bruta com o avanço da maturidade das plantas, provavelmente, se deve ao efeito de diluição dessa na matéria seca (MS) produzida (Gomide, 1976). Por outro lado, os teores de fibra encontrados na matéria seca de gramíneas forrageiras tropicais têm sido utilizados como índice negativo de qualidade (Matos, 1989; Palhano \& Haddad, 1992; Soest, 1994). Palhano \& Haddad (1992), avaliando o valor nutritivo do 'Coastcross' em diferentes idades de corte $(20,30,40,50$ e 70 dias), observaram teores de fibra detergente neutro (FDN) crescentes variando de $68,70 \%$ aos 20 dias até $80,55 \%$ aos 70 dias.

Segundo Hill et al. (1998), apesar da forragem de 'Tifton 85 ' apresentar alto teor de fibra em detergente neutro, a digestibilidade da mesma é alta, apresentando menores impedimentos físicos aos microorganismos do rúmen.

Com o presente trabalho objetivou-se avaliar a performance de 'Coastcross' (Cynodon dactylon (L.) Pers. cv. Coastal x Cynodon nlemfuensis Vanderyst var. robustus), 'Tifton 68' (Cynodon spp) e 'Tifton 85' (Cynodon spp) em quatro idades de corte $(28,42,56$ e 70 dias) sobre o rendimento e seu valor nutritivo.

\section{MATERIAL E MÉTODOS}

O experimento foi conduzido de novembro de 2000 a maio de 2001, em área do Departamento de Zoo- 
tecnia da Universidade Federal de Lavras (UFLA), Lavras, MG, situada a $21^{\circ} 14^{\prime}$ de latitude sul, $45^{\circ} 00^{\prime}$ de longitude oeste e altitude média local de $910 \mathrm{~m}$ (Castro Neto et al., 1980). O clima da região sul de Minas Gerais enquadra-se no tipo Cwb da classificação de Köppen, com precipitação média anual de $1.493,2 \mathrm{~mm}$, com temperaturas médias de 26,0 e $14,66^{\circ} \mathrm{C}$ para a máxima e a mínima, respectivamente (Vilela \& Ramalho, 1979).

O ensaio ocupou uma área total (inclusive os corredores) de $851 \mathrm{~m}^{2}$, tendo cada unidade experimental $33,0 \mathrm{~m}^{2}(11,0 \mathrm{~m} \times 3,0 \mathrm{~m})$. As idades de corte adotadas foram $28,42,56$ e 70 dias e cada unidade experimental ocupou uma área de $6 \mathrm{~m}^{2}$ (3,0 m x 2,0 m), com uma área útil de $1,0 \mathrm{~m}^{2}$ cada uma. Em 23/11/2000 foi realizada a sulcagem manual da área, seguida do plantio das gramíneas e do corte de uniformização. Os cortes de avaliação das gramíneas forrageiras foram feitos nas idades de 28, 42, 56 ( 2 cortes) e 70 dias (um apenas). Para tal, em uma área útil de $u m \mathrm{~m}^{2}$ cortaram-se manualmente, com cutelo a $10 \mathrm{~cm}$ do nível do solo, amostras de cerca de $500 \mathrm{~g}$, sendo conservadas em sacolas de papel. Essas amostras foram a "posteriori" pré-secas em estufa de circulação forçada, à temperatura de $65^{\circ} \mathrm{C}$, por um período de 72 horas, seguindo-se a sua moagem e acondicionamento em potes de plástico para análises posteriores.

Para a determinação dos teores de matéria seca (MS), foi utilizada a técnica gravimétrica, com o emprego de calor, utilizando-se duas fases: pré-secagem, seguida de secagem definitiva em estufa a $105^{\circ} \mathrm{C}$, por 12 horas, ou até peso constante (AOAC, 1990). Com o teor de MS e corrigindo-se a produção de matéria verde de cada subparcela, foram estimados os rendimentos de MS por hectare.
A determinação dos teores de proteína bruta (PB) foi efetuada conforme técnica da AOAC (1990). Os teores de fibra detergente neutro (FDN) foram determinados conforme método de Van Soest (AOAC, 1990). A determinação da digestibilidade "in vitro" da MS foi efetuada com o emprego da técnica dos dois estágios, de acordo com a técnica de Tilley \& Terry, descrita por Silva (1990).

O delineamento experimental utilizado foi o de blocos ao acaso, em esquema de parcelas subdivididas, sendo as gramíneas (= 3 tratamentos) alocadas nas parcelas e as idades de corte alocadas nas subparcelas, com cinco repetições. Os dados das características biológicas (matéria seca, proteína bruta, fibra detergente neutro e digestibilidade "in vitro da matéria seca e cultivares de gramíneas) foram submetidos à análise de variância (ANAVA) e as médias de tratamentos foram submetidas ao teste de médias de Scott \& Knott $(\mathrm{P}<0,05)$ (Scott \& Knott, 1974). Em razão das idades de corte das gramíneas, além da ANAVA, foi feita análise de regressão (P $<0,05)$ (Ribeiro Jr., 1999).

\section{RESULTADOS E DISCUSSÃO}

Observou-se que não houve interação entre as cultivares estudadas e as idade de corte para todas as características biológicas estudadas (Tabelas 1 e 2). Entretanto, independentemente da cultivar de gramínea, o rendimento de MS foi afetado $(\mathrm{P}<0,01)$ pela idade de corte dos capins, seguindo modelo quadrático. Assim, períodos iniciais de desenvolvimento dos capins apresentaram-se com baixo teor de matéria seca, a qual aumentou de uma idade a outra, atingindo valores máximos aos 70 dias de desenvolvimento (Figura 1).

TABELA 1 - Resumo da análise de variância da matéria seca, proteína e FDN, em função de gramíneas e idades de corte.

\begin{tabular}{|c|c|c|c|c|}
\hline \multirow{2}{*}{ FV } & \multirow{2}{*}{ GL } & \multicolumn{3}{|c|}{ Quadrado Médio } \\
\hline & & Matéria seca & FDN & Proteína bruta \\
\hline Blocos & 4 & 5,19 & 4,14 & 1,90 \\
\hline Cultivares de gramíneas & 2 & $0,513 \mathrm{~ns}$ & $17,11^{*}$ & $1,63 \mathrm{~ns}$ \\
\hline Erro (A) & 8 & 2,073 & 2,67 & 2,07 \\
\hline Idade de corte & 3 & $217,37 * *$ & $23,39 *$ & $109,06 * *$ \\
\hline Capins $\mathrm{x}$ Idade de corte & 6 & $0,20 \mathrm{~ns}$ & $4,66 \mathrm{~ns}$ & $1,09 \mathrm{~ns}$ \\
\hline Erro(B) & 36 & 0,55 & 4,04 & 0,48 \\
\hline $\mathrm{CV}(\%)$ & - & 13,06 & 2,48 & 5,12 \\
\hline
\end{tabular}


Em função das cultivares de gramínea, constatou-se que todas apresentaram teor semelhante de matéria seca (Tabela 3). Dessa forma, gramíneas do gênero Cynodon com até 70 dias de idade renderam, em média, 5,69 toneladas de matéria seca/hectar (Tabela $1)$.

Alvim et al. (1998c) obtiveram produção de 3,37 t/ha de MS para 'Coastcross' com período de corte de 2 a 7 semanas, valor que é semelhante ao obtido em nosso trabalho. Por outro lado, Alvim et al. (1998a) observaram rendimentos médios de 1,$9 ; 5,0$ e 6,3 t/ha de MS para capim da cultivar Tifton 85 aos 15, 28 e 42 dias de idade, valores que são próximos aos deste trabalho. Alvim et al. (1998b) obtiveram rendimentos próximos aos obtidos no presente estudo quando avaliaram a cultivar Tifton 68 nas idades de 15, 28 e 42 dias, obtendo rendimentos de 2,2; 5,9 e 5,8 t/ha de MS, respectivamente.

TABELA 2 - Resumo da análise de variância FDA e digestibilidade "in vitro" da matéria seca, em função de gramíneas e idades de corte.

\begin{tabular}{lccc}
\hline \multirow{2}{*}{ FV } & GL & \multicolumn{2}{c}{ Quadrado Médio } \\
\cline { 3 - 4 } & & FDA & Digestibilidade in vitro da matéria seca \\
\hline Blocos & 4 & 6,01 & 5,28 \\
Cultivares de gramíneas & 2 & $3,79 \mathrm{~ns}$ & $209,67^{* *}$ \\
Erro (A) & 8 & 4,36 & 7,72 \\
Idade de corte & 3 & $54,90^{* *}$ & $516,63^{* *}$ \\
Capins x Idade de corte & 6 & $3,35 \mathrm{~ns}$ & $4,87 \mathrm{~ns}$ \\
Erro (B) & 36 & 3,49 & 7,22 \\
\hline C. V $(\%)$ & - & 5,09 & 4,51 \\
\hline
\end{tabular}

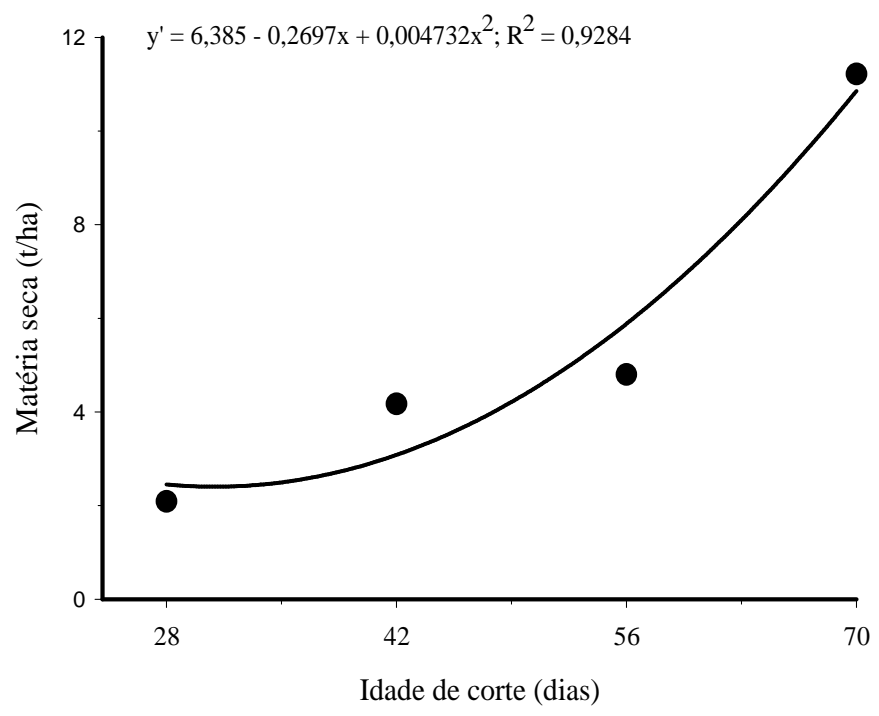

FIGURA 1 - Matéria seca (ton/ha) (Média geral), em função das idades de corte. 
Independente da idade de corte, houve efeito das cultivares $(\mathrm{P}<0,01)$ no teor de PB (Tabela 4). De forma semelhante, observou-se que houve efeito da idade de corte no teor de PB. Assim, constatou-se que ocorreu um decréscimo linear de $0,14 \%$ no teor de PB para cada dia de maturidade das gramíneas avaliadas (Figura 2). A mais tenra idade (28 dias) foi a que apresentou o maior teor de PB (17,18\%). Para as idades de 42, 56 e 70 dias, os teores de PB foram decrescentes e iguais a 13,85 ; 12,05 e 11,04\%, respectivamente (Figura 2).

Independentemente do estádio de maturidade, o 'Tifton 68' apresentou maior teor de proteína bruta $(13,84 \%)$ que 'Tifton 85 ' e 'Coastcross', os quais foram semelhantes entre si para essa característica biológica (13,47 e 13,27\%, respectivamente) (Tabela 4).

Alvim et al. (1998a), estudando o comportamento de 'Tifton 85', encontraram teores de PB decrescentes de 7,7; 7,5 e 7,2\% nas idades de 14, 28 e 42 dias. De igual modo, Alvim et al. (1998c) encontraram teores de PB de 15,7 a 10,9\% na MS de 'Coastcross', nas frequiências de corte de 14 a 49 dias.
Houve efeito significativo $(\mathrm{P}<0,05)$ para gramíneas e idades de corte, de forma independente, sobre os teores de FDN na MS das gramíneas estudadas (Tabela 5; Figura 3). As três gramíneas estudadas apresentaram incrementos de FDN com o avanço do estádio de maturidade. Por sua vez, a cv. Tifton 85 , independentemente da idade de rebrota, apresentou maior teor de FDN que os demais, os quais foram semelhantes entre si (Tabela $5)$.

Oliveira et al. (2000) registrou teor máximo de FDN de 79,24\% aos 51 dias de rebrota, quando avaliou o Tifton 85 em Viçosa - MG, sendo esse valor ligeiramente inferior ao obtido no presente ensaio, à idade de 56 dias (82,19\%). Segundo Wilkins (1969) e Reis \& Rodrigues (1993), os teores de FDN aumentam com a maturidade das plantas, e altas temperaturas assumem papel fundamental nesse processo. Neste trabalho, provavelmente temperaturas mais elevadas associadas com períodos mais prolongados de estresse hídrico na idade de 56 dias podem ser indicadas como a causa dos maiores valores de FDN observados.

TABELA 3 - Rendimento de matéria seca (MS) (t/ha) de gramíneas, em função da idade de corte.

\begin{tabular}{lccccc}
\hline \multirow{2}{*}{ Cultivares } & \multicolumn{4}{c}{ Idade de corte (dias) * } & \multirow{2}{*}{ Média geral* } \\
\cline { 2 - 5 } & $\mathbf{2 8}$ & $\mathbf{4 2}$ & $\mathbf{5 6}$ & $\mathbf{7 0}$ & \\
\hline Coastcross & 2,24 & 4,95 & 5,17 & 11,13 & 5,87 \\
Tifton 68 & 2,09 & 4,17 & 4,80 & 11,22 & 5,57 \\
Tifton 85 & 2,12 & 4,64 & 4,84 & 10,92 & 5,63 \\
\hline Média geral & 2,15 & 4,59 & 4,94 & 11,09 & - \\
\hline
\end{tabular}

* Médias são semelhantes a P>0,95.

TABELA 4 - Teor de proteína bruta (PB) (\%) na matéria seca de gramíneas, em função da idade de corte.

\begin{tabular}{|c|c|c|c|c|c|}
\hline \multirow{2}{*}{ Cultivares } & \multicolumn{4}{|c|}{ Idade de corte (dias) } & \multirow{2}{*}{ Média gera } \\
\hline & 28 & 42 & 56 & 70 & \\
\hline Coastcross & 16,81 & 13,88 & 11,42 & 10,98 & $13,27 \mathrm{~b}$ \\
\hline Tifton 68 & 17,91 & 14,22 & 12,49 & 10,73 & $13,84 \mathrm{a}$ \\
\hline Tifton 85 & 16,81 & 13,45 & 12,23 & 11,41 & $13,47 \mathrm{~b}$ \\
\hline Média geral & 17,18 & 13,85 & 12,05 & 11,04 & - \\
\hline
\end{tabular}

*Médias seguidas pela mesma letra minúscula na coluna não diferem entre si pelo teste de Scott - Knott a $5 \%$ de probabilidade. 


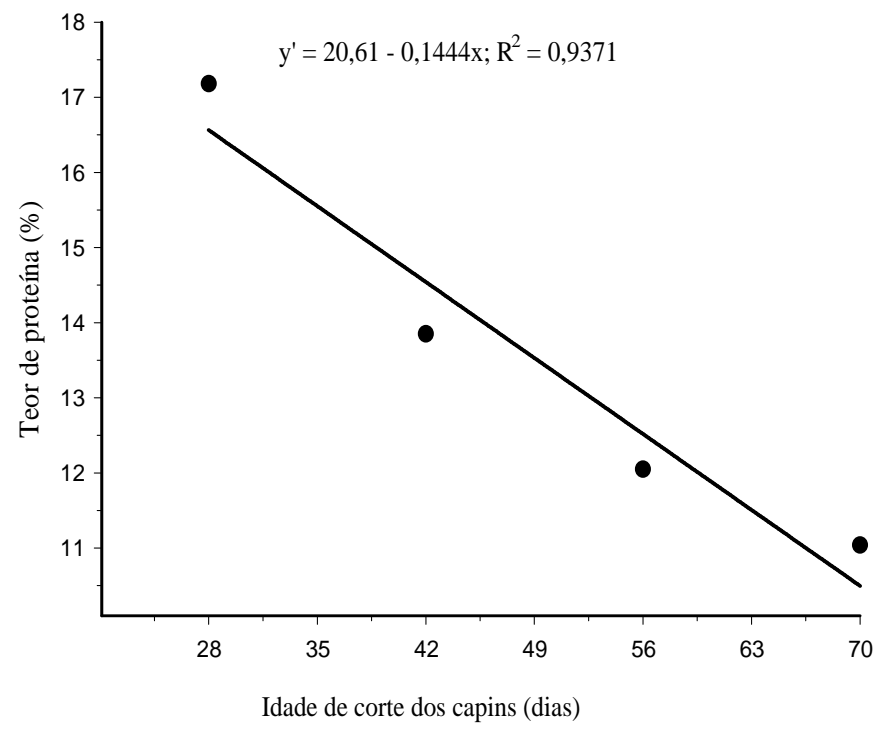

FIGURA 2 - Teor de proteína bruta na matéria seca de 'Coastcross', 'Tifton 68' e 'Tifton 85' (Média geral), em função da idade de corte.

TABELA 5 - Teor de fibra detergente neutro (FDN) (\%) na matéria seca, em função de gramíneas e da idade de corte.

\begin{tabular}{|c|c|c|c|c|c|}
\hline \multirow{2}{*}{ Cultivares } & \multicolumn{4}{|c|}{ Idade de corte (dias) } & \multirow{2}{*}{ Média geral } \\
\hline & 28 & 42 & 56 & 70 & \\
\hline Coastcross & 80,65 & 79,34 & 82,32 & 80,53 & $80,71 \mathrm{~b}$ \\
\hline Tifton 68 & 77,65 & 79,88 & 81,31 & 81,81 & $80,16 \mathrm{~b}$ \\
\hline Tifton 85 & 80,66 & 81,13 & 82,95 & 83,12 & $81,97 \mathrm{a}$ \\
\hline Média geral & 79,65 & 80,11 & 82,19 & 81,82 & - \\
\hline
\end{tabular}

*Médias seguidas pela mesma letra minúscula na coluna não diferem entre si pelo teste de Scott - Knott a $5 \%$ de probabilidade.

Os teores de 79,65 e $81,82 \%$ de FDN para as idades de 28 e 70 dias foram superiores aos obtidos por Palhano \& Haddad (1992), ao estudarem, em Rio ClaroSP, 'Coastcross' no intervalo de 20 a 70 dias, quando registraram valores de 68,70 a $80,55 \%$.

De forma análoga às outras características estudadas, observou-se efeito significativo $(\mathrm{P}<0,01)$ das gramíneas e das idades de maturidade na característica, coeficiente de DIVMS (Tabela 6; Figura 4). Dessa forma, o maior coeficiente de DIVMS foi observado na cultivar Tifton 68 (63,13\%), seguindo-se Tifton $85(58,79 \%)$ e, finalmente, o Coastcross $(56,80 \%)$ (Tabela 6).
$\mathrm{O}$ incremento do coeficiente de digestibilidade "in vitro" ocorreu de forma quadrática negativa, tendo-se maior digestibilidade do material aos 28 dias de idade das gramíneas, seguida de queda em forma quadrática, até atingir o mínimo a 70 dias de idade dessas gramíneas (Figura 4). Isto é evidente pela alta representatividade do modelo quadrático $\left(\mathrm{R}^{2}=0,99\right)$ e pela alta significância $(\mathrm{P}<0,01)$ (Tabela 2$)$, podendo-se afirmar que a faixa de idade de máxima digestibilidade "in vitro" ocorreu de 28 até 42 dias de idade, abaixo da qual entra-se em uma faixa crítica (Figura 4). 


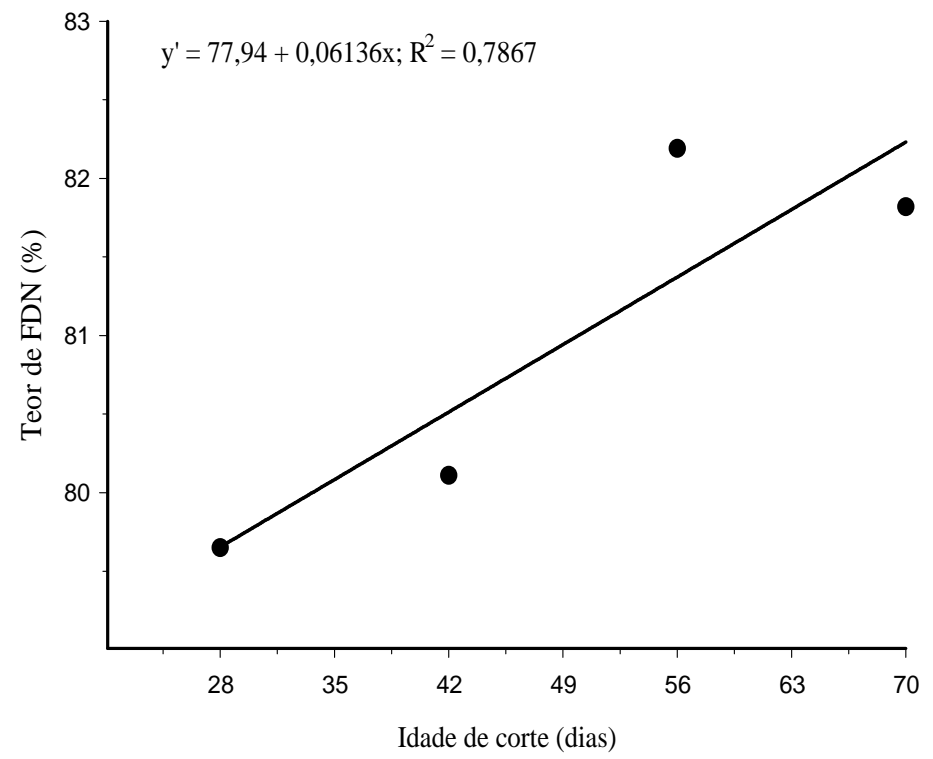

FIGURA 3 - Fibra em detergente neutro (FDN) na matéria seca de 'Coastcross', 'Tifton 68' e 'Tifton 85' (Média geral), em função da idade de corte.

TABELA 6 - Coeficiente de digestibilidade "in vitro" da matéria seca (DIVMS) (\%) em gramíneas, em função da idade de corte.

\begin{tabular}{|c|c|c|c|c|c|}
\hline \multirow{2}{*}{ Cultivares } & \multicolumn{4}{|c|}{ Idade de corte (dias) } & \multirow{2}{*}{ Média geral } \\
\hline & 28 & 42 & 56 & 70 & \\
\hline Coastcross & 62,84 & 60,59 & 56,47 & 47,30 & $56,80 \mathrm{c}$ \\
\hline Tifton 68 & 68,18 & 65,77 & 63,08 & 55,49 & 63,13 a \\
\hline Tifton 85 & 64,31 & 60,53 & 58,61 & 51,71 & $58,79 \mathrm{~b}$ \\
\hline Média geral & 65,11 & 62,30 & 59,39 & 51,50 & - \\
\hline
\end{tabular}

*Médias seguidas pela mesma letra minúscula na coluna não diferem entre si pelo teste de Scott - Knott a $5 \%$ de probabilidade.

Ao compararem híbridos do gênero Cynodon, Burton \& Monson (1984) observaram o mesmo comportamento do coeficiente de DIVMS deste estudo, registrando o valor mais alto para o 'Tifton 68' $(64,3 \%)$ e valores menores para 'Coastal' e 'Coastcross', 54,9 e 57,3\%, respectivamente.
Ribeiro et al. (1998), avaliando intervalos de corte de 28, 42 e 56 dias sobre a digestibilidade da MS de 'Tifton 85', observaram um decréscimo dos coeficientes da DIVMS em função da idade, registrando os valores respectivos de 62,$2 ; 57,1$ e $55,9 \%$, inferiores aos deste ensaio para a mesma gramínea. 


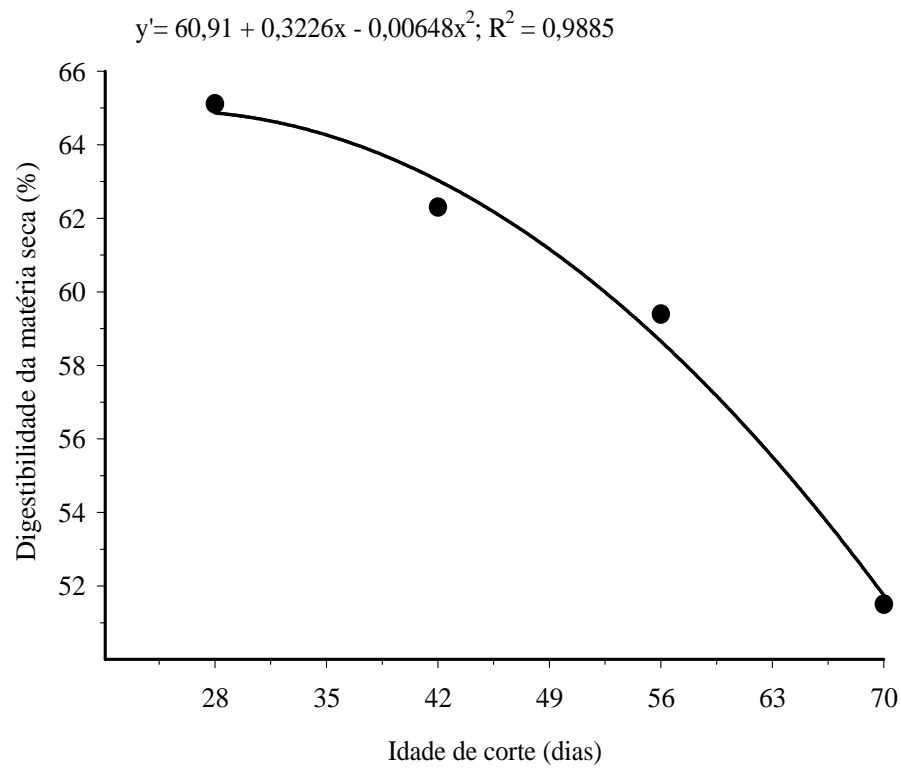

FIGURA 4 - Coeficientes de digestibilidade da matéria seca (DIVMS) (\%) (Média geral) em gramíneas, em função da idade de corte.

\section{CONCLUSÃO}

A performance das cultivares Tifton 68 , Tifton 85 e Coastcross é altamente afetada pela idade de corte. Entretanto, as primeiras duas apresentam rendimentos e composição química bem próxima, sendo superiores à cultivar Coastcross. Nas condições do sul de Minas Gerais, a melhor idade de corte ocorre entre 35 a 48 dias de idade dessas gramíneas.

\section{REFERÊNCIAS BIBLIOGRÁFICAS}

ALVIM, M. J.; BOTREL, M. A.; MARTINS, C. E.; COSER, A. C.; RESENDE, H.; VILELA, D. Efeito de doses de nitrogênio e de intervalos entre corte sobre a produção de matéria seca e teor de proteína bruta do Tifton 85. In: REUNIÃO ANUAL DA SOCIEDADE BRASILEIRA DE ZOOETCNIA, 35., 1998, Botucatu. Anais... Botucatu: SBZ, 1998a. p. 492-494.

ALVIM, M. J.; BOTREL, M. A.; MARTINS, C. E.; COSER, A. C.; RESENDE, H.; VILELA, D. Resposta do Coastcross (Cynodon dactylon (L.) Pers.) a diferentes doses de nitrogênio e intervalos de cortes. In: SIMPÓSIO SOBRE MANEJO DA PASTAGEM, 15., 1998, Piracicaba. Anais... Piracicaba: FEALQ, 1998b. p. 2354.
ALVIM, M. J.; XAVIER, D. F.; BOTREL, M. A.; MARTINS, C. E. Resposta do Coastcross (Cynodon dactylon (L.) Pers.) a diferentes doses de nitrogênio e intervalos de cortes. Revista Brasileira de Zootecnia, Viçosa, v. 27, n. 5, p. 829-836, set./out. 1998c.

ASSOCIATION OF OFFICIAL AGRICULTURAL CHEMISTS - AOAC. Official methods of analisys. 15. ed. Virginia, 1990. v. 1, 684 p.

BOTREL, M. A.; NOVAES, L. P.; ALVIM, M. J. Características de algumas gramíneas tropicais. Coronel Pacheco: EMBRAPA-CNPGL, 1998. 35 p. (EMBRAPA-CNPGL. Documentos, 66).

BURTON, G. W.; GATES, R. N.; HILL, G. M. Registration of Tifton 85 bermudagrass. Crop Science, Madison, v. 33, n. 3, p. 644-645, May/June 1993.

BURTON, G. W.; MONSON, W. G. Registration of Tifton 68 bermudagrass. Crop Science, Madison, v. 24, n. 6, p. 1211, Nov./Dec. 1984.

CASTRO NETO, P.; SEDIYAMA, G. C.; VILELA, E. A. Probabilidade de ocorrência de períodos secos em, Lavras, MG. Ciência e Prática, Lavras, v. 4, n. 1, p. 46-55, jan./jun. 1980. 
GOMIDE, J. A. Composição mineral de gramíneas e leguminosas forrageiras tropicais. In: SIMPÓSIO LATINO-AMERICANO SOBRE PESQUISA EM NUTRIÇÃO MINERAL DE RUMINANTES EM PASTAGENS, 1., 1976, Belo Horizonte. Anais... Belo Horizonte: EPAMIG, 1976. p. 20-33.

HILL, G. M.; GATES, R. N.; WEST, I. W.; MANDEBVU, P. Pesquisa com capim bermuda cv. 85 em ensaio de pastejo e de digestibilidade de feno com bovinos. In: SIMPÓSIO SOBRE MANEJO DA PASTAGEM, 15., 1998, Piracicaba. Anais... Piracicaba: FEALQ, 1998. p. 7-22.

MATOS, L. L. Utilização de fibra pelos ruminantes. In: MINI SIMPÓSIO DO COLÉGIO BRASILEIRO DE NUTRIÇÃO ANIMAL, 2., 1989, Jaboticabal. Anais... Jaboticabal: Colégio Brasileiro de Nutrição Animal, 1989. p. 67-92.

OLIVEIRA, M. A. de.; PEREIRA, O. G.; GARCIA, R.; OBEID, J. A.; CECON, P. R.; MORAES, S. A. de.; SILVEIRA, P. R. da. Rendimento e valor nutritivo do capim Tifton 85 (Cynodon spp.) em diferentes idades de rebrota. Revista Brasileira de Zootecnia, Viçosa, v. 29, n. 6, p. 1949-1960, nov./dez. 2000.

PALHANO, A. L.; HADDAD, C. M. Exigências nutricionais e valor nutritivo de Cynodon dactylon (L.) Pers. cv. Coastcross $\mathrm{N}^{\circ} 1$. Pesquisa Agropecuária Brasileira, Brasília, v. 27, n. 10, p. 1429-1438, out. 1992.

REIS, R. A.; RODRIGUES, L. R. A. Valor nutritivo de plantas forrageiras. Jaboticabal: [s.n.], 1993. 26 p.

RIBEIRO JÚNIOR, J. I. Análises estatísticas no SAEG 8.0. Viçosa: UFV, 1999. 97 p. Apostila.
RIBEIRO, K. R.; PEREIRA，O. G.; GARCIA，R.; VALADARES FILHO, S. de C.; CECOM, P. R.; MOREIRA, A. L.; HENRIQUES, L. T.; FREITAS, E. V. V. Rendimento forrageiro e valor nutritivo do capim Tifton 85 , em três freqüências de corte, sob diferentes doses de nitrogênio. In: REUNIÃO ANUAL DA SOCIEDADE BRASILEIRA DE ZOOETCNIA, 35., 1998, Botucatu. Anais... Botucatu: SBZ, 1998. p. 542543.

SILVA, D. J. Análise de alimentos: métodos químicos e biológicos. 2. ed. Viçosa: UFV, 1990. 165 p.

SCOTT, A. J.; KNOTT, M. A. A cluster analysis method for grouping means in the analysis of variance. Biometrics, Raleigh, v. 30, n. 2, p. 507-512, 1974.

SOEST, P. J. V. Nutritional ecology of the ruminant. 2. ed. Corvalis: O e B Books, 1994. 476 p.

VILELA, D.; ALVIM, M. J. Manejo de pastagem do gênero Cynodon: introdução, caracterização e evolução do uso no Brasil. In: SIMPÓSIO SOBRE MANEJO DA PASTAGEM, 15., 1998, Piracicaba. Anais... Piracicaba: FEALQ, 1998. p. 23-54.

VILELA, E. A.; RAMALHO, M. A. P. Análise das temperaturas e precipitações pluviométricas de Lavras, Minas Gerais. Ciência e Prática, Lavras, v. 3, n. 1, p. 71-79, jan./jun. 1979

WILKINS, R. J. The potential digestibility of cellulose in forages and faces. Journal of Agricultural Science, Cambridge, v. 73, p. 57-64, 1969. 